\title{
Semantic and acoustic clustering under modified blocked-presentation procedures*
}

\author{
WILLIAM E. FORRESTER \\ State Liniversity. College at Oswego, N.Y. 13126
}

A mixed list containing four sets of semantically related words ( 3 words per set), four sets of acoustically related words ( 3 words per set), and 12 unrelated words was presented to Ss for free recall. Items were presented to $S$ in either a completely randomized order or under a modified blocked-presentation precedure. In the latter procedure, the three components of the list were presented in blocked fashion, but the items within each component were ordered randomly. The results indicated that semantic clustering occurred in all conditions of list presentation while acoustic clustering failed to occur in any.

In a previously reported study by Forrester \& King (1971), a mixed list containing four sets of semantically related items ( 3 words per set), four sets of acoustically related items ( 3 words per set), and 12 unrelated words was presented to Ss for free recall. The results indicated that semantically related items were clustered to a significant degree while acoustically related items were not. In view of the fact that Bousfield \& Wicklund (1969) had found significant acoustic clustering with a homogeneous, i.e., unmixed, list, Forrester and King's mixed-list results may simply indicate that S's "preference" is for the semantic rather than the acoustic mode of organization. Support for this conclusion was subsequently provided by Dolinsky (1972), who examined semantic-acoustic clustering differences for lists where either one or both modes of organization were available to $\mathrm{S}$. Although significant, but small, amounts of acoustic clustering were found when no obvious semantic relationships were present in the list, Dolinsky found only chance levels of acoustic clustering when Ss were able to organize materials along either dimension.

It is possible, as Dolinsky (1972) points out, that the pressence of semantically related items in a list focuses $S$ 's attention on those items at the expense of any acoustically related items that are in the list. Procedures that increase the salience of the acoustic dimension might then be expected to increase the extent of acoustic clustering. One procedure that is presumed to increase the salience of organizational cues is the blocked-presentation method. Previous research (e.g.. Cofer, Bruce, \& Reicher, 1966) has shown that clustering of semantically related items is increased when category instances are presented to $\mathrm{S}$ contiguously (i.e.. blocked) rather than randomly. Evidence to suggest that

*This research was supported in part by Grant HD06420 from the National Institute of Child Health and Human Development. blocking of acoustically related words also has facilitative effects was presented by Bruce \& Crowley (1970).

In the present study, the blocked-presentation procedure was modified such that the semantic, acoustic, and unrelated components of Forrester \& King's (1971) mixed list were presented in blocked fashion. The items within each component, however, were randomly ordered. While this procedure does not bring category members into contiguous input positions, it does serve to decrease the potential number of items which might intervene between category instances relative to that found in the completely randomized case. The assumption underlying use of the modified blocked-presentation procedure was that the occurrence of acoustic clustering under such procedures would provide stronger evidence that Ss use acoustic cues than would the finding of clustering under completely blocked presentation. Since it is possible that the order in which semantic, acoustic, and unrelated components of a mixed list are presented might lead to the development of a set on the part of $\mathrm{S}$ to organize items along a given dimension, all possible orderings of the three components were included in the present study.

\section{METHOD \\ Subjects}

A total of 84 undergraduates from the State University College at Oswego served as Ss. All Ss were enrolled in the introductory psychology course, with none having served in any previous verbal-learning experiments.

\section{Materials}

The learning material consisted of a 36-word list containing four 3-item sets of semantically related words. four 3-item sets of acoustically related words, and 12 unrelated words. Items used in the semantic component were selected from Battig \& Montague's (1969) category norms. Sets of acoustically related items were constructed from words which rhymed but were not formally similar (e.g.. KEY, TEA, SHE). All words had Thorndike-Lorge frequencies of $\mathrm{A}$ or $\mathrm{AA}$, with the three components of the list equated for frequency. The specific words used in the study may be found in Forrester \& King (1971).

\section{Design}

One variable in the experimental design was relatedness of words included in the learning materials. The three levels of this within-Ss factor were defined by the three components of the list. Presentation order of list items was varied as a between-Ss factor. A total of seven groups of $S s(N=12)$ were formed on the basis of a randomized schedule sheet and $S ` s$ order of appearance in the laboratory. For six of these groups. the presentation order was such that the semantic (S). acoustic (A). and unrelated $(U)$ components of the list appeared in successive thirds of input. These groups will be referred to as SAL. SLA. ASU. AUS. USA, and UAS. Components of the list appearing in 
Table 1

Means for Observed and Expected Stimulus Category Repetitions

\begin{tabular}{|c|c|c|c|c|c|c|c|c|}
\hline \multirow{2}{*}{$\begin{array}{l}\text { Cluster- } \\
\text { ing Mode }\end{array}$} & & \multicolumn{7}{|c|}{ Presentation Order Conditions } \\
\hline & & S.AC & SLA & $\mathrm{ASU}$ & AUS & USA & LAS & $\mathrm{R}$ \\
\hline Semantic & $\begin{array}{l}\mathrm{O} \\
\mathrm{E}\end{array}$ & $\begin{array}{c}1.42 \div \\
.56\end{array}$ & $\begin{array}{c}1.25 \div \\
.33\end{array}$ & $\begin{array}{l}.83 \div \\
.33\end{array}$ & $\begin{array}{l}.50^{*} \\
.17\end{array}$ & $\begin{array}{c}1.25 \div \\
.36\end{array}$ & $\begin{array}{l}.92^{*} \\
.33\end{array}$ & $\begin{array}{l}.83 \\
.45\end{array}$ \\
\hline Acoustic & $\begin{array}{l}\mathrm{O} \\
\mathrm{E}\end{array}$ & $\begin{array}{l}.33 \\
.06 \\
\end{array}$ & $\begin{array}{l}.33 \\
.22 \\
\end{array}$ & $\begin{array}{l}.17 \\
.20 \\
\end{array}$ & $\begin{array}{r}.25 \\
.22 \\
\end{array}$ & $\begin{array}{r}.25 \\
.24 \\
\end{array}$ & $\begin{array}{l}.17 \\
.16 \\
\end{array}$ & $\begin{array}{l}.00 \\
.08 \\
\end{array}$ \\
\hline
\end{tabular}

successive thirds of input are indicated by reading from left to right for each group. For the seventh group (Group R). list items were presented in a completely randomized order.

\section{Procedure}

Items were presented to $S$ by means of a Stowe memory drum with presentation rate set at $2 \mathrm{sec} / \mathrm{item}$. For Group R. the order of presenattion of items was randomized subject to the restriction that no two items from the same semantic or acoustic set appear in successive input positions. For the six blocked-presentation conditions, items within each component were ordered randomly subject to the aforementioned restriction.

Preceding presentation of the list, $\mathrm{S}$ was given instructions appropriate to free recall. Immediately following list presentation. $\mathrm{S}$ was given $2 \mathrm{~min}$ for written recall.

\section{RESULTS AND DISCUSSION}

Each S's clustering data were scored by computing the difference between that S's observed and expected number of stimulus category repetitions. The latter values were determined for each $\mathrm{S}$ by generating 500 random permutations of that S's recall on an IBM 1130 computer. Means of observed and expected stimulus category repetitions for the seven groups are shown in Table 1.

Difference scores (observed minus expected) were analyzed for each group by means of $t$ tests. As shown in Table 1, significant amounts of semantic clustering were found for all groups. Significant ts (assessed by a one-tailed test) ranged from $t(11)=1.94, p<.05$, for
Group Alis to $t(11)=4.68, p<.005$. for Group LSA. Comparable analyses for the acoustic component revealed that none of the groups clustered to a significant degree (all ts $<1.18$ ).

The finding that semantic clustering exceeded chance levels in all presentation-order conditions while acoustic clustering did not suggests that the presentation-order variable had no differential effect on clustering behavior. In order to assess relative clustering differences in a more direct way. however. the data were subjected to analysis of variance. Results of the analysis indicated that semantic clustering exceeded acoustic clustering in all groups. $F(6.77)=52.88 . p<.001$, with neither the main effect of presentation order nor the Presentation Order by List Components interaction being significant.

The present results may be summarized quite simply: semantic clustering occurred in comparable amounts under all conditions of list presentation, while acoustic clustering failed to occur in any. These results, together with those of earlier investigators (Dolinsky. 1972: Forrester \& King, 1971), thus indicate that Ss do not organize list-items on the basis of acoustic attributes if semantic relationships are present in the list.

\section{REFERENCES}

Battig, W. F., \& Montague, W. E. Category norms for verbal items in 56 categories: $A$ replication and extension of the Connecticut norms. Journal of Experimental Psychology Monograph, 1969, 80, (3, Part 2).

Bousfield, W. A., \& Wicklund, D. A. Rhyme as a determinant of clustering. Pshchonomic Science, 1969, 16, 183-184.

Bruce, D., \& Crowley, J. J. Acoustic similarity effects on retrieval from secondary memory. Journal of Verbal Learning \& Verbal Behavior, 1970, 9, 190-196.

Cofer, C. N., Bruce, D. R., \& Reicher, G. M. Clustering in free recall as a function of certain methodological variations. Journal of Experimental Psychology, 1966, 71, 858-866.

Dolinsky, R. Clustering and free recall with alternative organizational cues. Journal of Experimental Psychology, $1972,95,159-163$.

Forrester, W. E., \& King, D. J. Effects of semantic and acoustic relatedness on free recall and clustering. Journal of Experimental Psychology, 1971, 88, 16-19.

(Received for publication June 6. 1973.) 